\title{
Clinical Evaluation of Topical Lotion Containing 2-Aza-8-Oxohypoxanthine on Skin Barrier Function against Water Loss
}

\author{
Hisae Aoshima ${ }^{1, *}$, Rinta Ibuki ${ }^{1}$, Masayuki Ito ${ }^{1}$ and Hirokazu Kawagishi ${ }^{2,3,4, *}$ \\ 1 Department of Research and Development, Vitamin C60 BioResearch Corp, Nihonbashidori-nichoume Bldg, \\ 4F 2-2-6 Nihonbashi Chuo-ku, Tokyo 103-0027, Japan; rinta.ibuki@vc60.com (R.I.); \\ masayuki.ito@vc60.com (M.I.) \\ 2 Research Institute of Green Science and Technology, Shizuoka University, \\ 836 Ohya, Suruga-ku, Shizuoka 422-8529, Japan \\ 3 Graduate School of Science and Technology, Shizuoka University, \\ 836 Ohya, Suruga-ku, Shizuoka 422-8529, Japan \\ 4 Graduate School of Integrated Science and Technology, Shizuoka University, \\ 836 Ohya, Suruga-ku, Shizuoka 422-8529, Japan \\ * Correspondence: hisae.aoshima@vc60.com (H.A.); kawagishi.hirokazu@shizuoka.ac.jp (H.K.); \\ Tel.: +81-3-3517-3253 (H.A.); +81-54-238-4885 (H.K.)
}

check for updates

Citation: Aoshima, H.; Ibuki, R.; Ito, M.; Kawagishi, H. Clinical Evaluation of Topical Lotion Containing 2-Aza-8-Oxohypoxanthine on Skin Barrier Function against Water Loss. Cosmetics 2021, 8, 83. https:// doi.org/10.3390/cosmetics8030083

Academic Editor: Sekyoo Jeong

Received: 19 August 2021

Accepted: 3 September 2021

Published: 5 September 2021

Publisher's Note: MDPI stays neutral with regard to jurisdictional claims in published maps and institutional affiliations.

Copyright: (c) 2021 by the authors. Licensee MDPI, Basel, Switzerland. This article is an open access article distributed under the terms and conditions of the Creative Commons Attribution (CC BY) license (https:// creativecommons.org/licenses/by/ $4.0 /)$.

\begin{abstract}
A clinical study was conducted to evaluate the efficacy of 2-aza-8-oxohypoxanthine (AOH) on human skin in a double-blind, placebo-controlled, and split-face comparative trial. To this end, a topical lotion containing $0.1 \%$ of $\mathrm{AOH}$ and its placebo formulation were applied in 20 Japanese subjects (age: $41-58$ years, average: $48.4 \pm 4.7$ years) to their faces daily for eight weeks. The moisture content in the stratum corneum and the trans-epidermal water loss (TEWL) were measured at the beginning of the study and after eight weeks. The results obtained upon comparing the data of the two measuring points showed that the $0.1 \% \mathrm{AOH}$ lotion caused a statistically significant larger decrease in TEWL after eight weeks. Moreover, the $0.1 \% \mathrm{AOH}$ lotion produced a larger increase in the moisture content in the stratum corneum after eight weeks, although there was no statistical difference between the two formulations. These results clearly indicate that $\mathrm{AOH}$ is effective as a cosmetic agent with a skin barrier function against water loss.
\end{abstract}

Keywords: fairy chemicals; $\mathrm{AOH}$; clinical trial; moisture content; stratum corneum; trans-epidermal water loss; TEWL

\section{Introduction}

When one observes a lawn, one may notice a naturally occurring thicker ring compared to the surrounding turf grass. Mushrooms may also grow within the same circle. According to Western legends, fairies were said to form these rings and dance in them; hence this phenomenon is known as "fairy rings" [1-3]. The cause of the phenomenon of the formation of fairy rings had long remained a mystery before our study in 2010; we discovered a substance that is involved in the formation of fairy rings-2-azahypoxanthin (AHX), a plant growth stimulant, in the mycelial culture broth of Lepista sordida, a kind of fairyring-forming mushroom. In addition, imidazole-4-carboxamide (ICA), which inhibits the growth of turfgrass, was also found in the broth $[4,5]$. Furthermore, we found that AHX is converted to 2-aza-8-oxohypoxanthine $(\mathrm{AOH})$ in plants (Figure 1) [6]. We named AHX, ICA, and AOH "Fairy Chemicals (FCs)" after the title of the Nature article that discussed our research [7]. Subsequent studies have revealed that FCs are endogenous in the edible parts of the three major cereal grains (rice, wheat, and corn) [6] and that people have been eating FCs since ancient times. Furthermore, it was found that FCs increased the yield of crops such as rice and wheat $[4,8,9]$. These results suggest that FCs may be a new family of plant hormones [10,11]. 
Kinetin

(a) AHX<smiles>O=c1[nH]nnc2[nH]cnc12</smiles>

(b) ICA<smiles>NC(=O)c1c[nH]cn1</smiles>

(c) $\mathrm{AOH}$<smiles>O=c1[nH]c2nn[nH]c(=O)c2[nH]1</smiles><smiles>c1coc(CNc2ncnc3[nH]cnc23)c1</smiles>

Figure 1. Structures of (a) 2-azahypoxanthine (AHX), (b) imidazole-4-carboxamide (ICA), (c) 2-aza-8-oxohypoxanthine $(\mathrm{AOH})$, and kinetin.

Kinetin is a member of a family of plant growth hormones called cytokinins (Figure 1). Stanley B. Levy of Revlon Consumer Products, Inc. described kinetin as a useful compound for human skin aging [12]. Kinetin has been a widely used ingredient in cosmetics and medicinal cosmetics for a long time. Since FCs are plant-growth-promoting substances with purine skeletons, like kinetin, we thought that they had potential as cosmetic ingredients and examined their safety and effectiveness according to the idea.

Among the three types of FCs, we focused on $\mathrm{AOH}$ and conducted the Ames test, in vitro skin irritation and sensitization (direct peptide reactivity assay: DPRA, human cell line activation test: $\mathrm{h}$-CLAT, and KeratinoSens ${ }^{\mathrm{TM}}$ methods), in vitro phototoxicity, human patch test, human phototoxicity and photosensitization, and human skin sensitization test (repeated insult patch test: RIPT) to verify the safety of AOH. No adverse reactions to $\mathrm{AOH}$ were observed in all safety evaluations, suggesting that $\mathrm{AOH}$ can be used safely as a cosmetic ingredient $[13,14]$.

In a previous study that evaluated the efficacy of 2-aza-8-oxohypoxanthine $(\mathrm{AOH})$ as a cosmetic ingredient, its effects on normal human epidermal keratinocytes (NHEK) were investigated. The results revealed that a $24 \mathrm{~h}$ exposure of $\mathrm{AOH}$ to NHEK did not show any cytotoxicity $(<500 \mu \mathrm{g} / \mathrm{mL})$. When NHEK was exposed to $\mathrm{AOH}$ for $48 \mathrm{~h}$, cells proliferated significantly at levels below $31.3 \mu \mathrm{g} / \mathrm{mL}$, indicating that $\mathrm{AOH}$ has a cellular activation effect [15]. A DNA microarray analysis of genes involved in skin aging and diseases using NHEK revealed that the expression levels of genes involved in skin barrier function were generally increased [15]. In particular, the expression levels of KRT1 and KRT10, which are differentiation markers of the stratum corneum, were statistically significantly increased at $30 \mu \mathrm{g} / \mathrm{mL}$ of $\mathrm{AOH}$ or higher, suggesting that $\mathrm{AOH}$ may contribute to the promotion of stratum corneum differentiation. The expression level of HAS3, a type of hyaluronic acid synthase, also increased in a concentration-dependent manner with the addition of $\mathrm{AOH}$, suggesting its moisturizing effect. Thus, $\mathrm{AOH}$ may play a role in improving, or enhancing, the barrier function of the skin. Based on the results of this study, we conducted a clinical trial on healthy subjects to further ascertain the potential of $\mathrm{AOH}$ as a cosmetic ingredient. If this clinical study showed that the application of $\mathrm{AOH}$ increases the stratum corneum water content and decreases trans-epidermal water loss (TEWL) values, it would demonstrate the results of the DNA microarray in human skin. This study was the first report of the application of $\mathrm{AOH}$ to human skin.

\section{Materials and Methods}

\subsection{Preparation of Test Substance}

$\mathrm{AOH}$ was synthesized from 5-aminoimidazole-4-carboxamide, as described in a previous study [16]. Methyl $p$-hydroxybenzoate (final $0.4 \%$, FUJIFILM Wako Pure Chemical Corporation, Tokyo, Japan) was added to 1.3-butanediol (final 5\%, ITO Co., Ltd., Tokyo, Japan) and heated until it dissolved. Phenoxyethanol (final 0.3\%, FUJIFILM Wako Pure 
Chemical Corporation), xanthan gum (KELCOL CG LAX-T, Sansho Co., Ltd., Osaka, Japan), and polyoxyethylene hydrogenated castor oil 60 (final 0.2\%, Nikko Chemicals Co., Ltd., Tokyo, Japan) were added to the 1.3-butanediol solution. AOH (final 0.1\%) in sodium phosphate buffer ( $\mathrm{pH} 7.0$, final $10 \mathrm{mM}$, FUJIFILM Wako Pure Chemical Corporation) and purified water (final 33.8\%) were added to the solution. A formula with the composition described above, but without any $\mathrm{AOH}$, was used as a placebo lotion.

\subsection{Clinical Trial}

\subsubsection{Selection of Subjects}

Subjects who met the following selection criteria were included:

(1) Women in their $40 \mathrm{~s}$ or $50 \mathrm{~s}$ at the time of consent;

(2) Those with wrinkles equivalent to wrinkle grade 1 to 3 at the corner of the right and left eyes;

(3) Those who could give written consent based on their own free will before the start of the study;

(4) Those who could give consent to the use of only the test sample in the designated area.

\subsubsection{Clinical Trial Study}

This clinical trial was conducted between 19 January and 25 March 2020, in Osaka, Japan. The test was a double-blind, placebo-controlled, split-face, left-right randomized trial. A total of 20 healthy Japanese women (age: $41-58$ years, average: $48.4 \pm 4.7$ years) were enrolled in the study. The subjects were not pregnant; did not habitually take topical medications, oral medications, or supplements; did not undergo hormone replacement therapy; did not have surgical procedures on the test site; and did not have experience in cosmetic medicine that would affect the test site. After washing their face twice in the morning and evening, the participants applied a lotion containing $0.1 \% \mathrm{AOH}$ to one half of their face and a placebo lotion to the other half for eight weeks.

\subsubsection{Evaluation and Statistical Analysis}

The stratum corneum moisture content of both cheeks was measured using SKICON200EX (YAYOI Co., Ltd., Tokyo, Japan). TEWL was measured using a Cyclone Moisture Evaporation Meter AS-CT1 (Asch Japan Co. Ltd., Tokyo, Japan). Measurements were taken at least thrice, and the average of three stable measurements was used. The statistical software IBM SPSS Statistics 25 (https:/ / www.ibm.com/products/spss-statistics, accessed on 4 September 2021) was used. A corresponding $t$-test was performed.

\section{Results}

A double-blind clinical study was conducted on 20 subjects, in which they applied $0.1 \% \mathrm{AOH}$ lotion to one half of their face and a placebo lotion to the other half for eight weeks. No adverse events were found to be causally related to the test substance during the application period.

The stratum corneum water content at the beginning of the study and after eight weeks is shown in Figure 2. A comparison of the above data revealed that the stratum corneum water content showed an increasing trend for both the $0.1 \% \mathrm{AOH}$ lotion and the placebo lotion. Comparing the application sites of the $0.1 \% \mathrm{AOH}$ lotion and placebo lotion after eight weeks revealed that the stratum corneum water content of the skin to which the $0.1 \% \mathrm{AOH}$ lotion was applied increased more. The results of TEWL measurements at the beginning of the study and after eight weeks are shown in Figure 3. The TEWL in the placebo lotion application group showed a decreasing trend $(p=0.063)$, while the TEWL in the $0.1 \% \mathrm{AOH}$ lotion application group showed a statistically significant decrease after eight weeks of application $(p=0.004)$. These results indicate that the lotion containing $0.1 \%$ $\mathrm{AOH}$ had a moisturizing function, as well as a barrier-function-improving or strengthening effect, compared to the placebo lotion. Through the comparison of stratum corneum water content after 8 weeks, it was shown that the value in the $0.1 \% \mathrm{AOH}$ lotion application 
group was higher than that in the placebo group. By comparing the TEWL values after 8 weeks, it was shown that the values in the $0.1 \% \mathrm{AOH}$ lotion application group were lower than those in the placebo application group. However, there was no statistically significant difference in either stratum corneum water content or TEWL values.

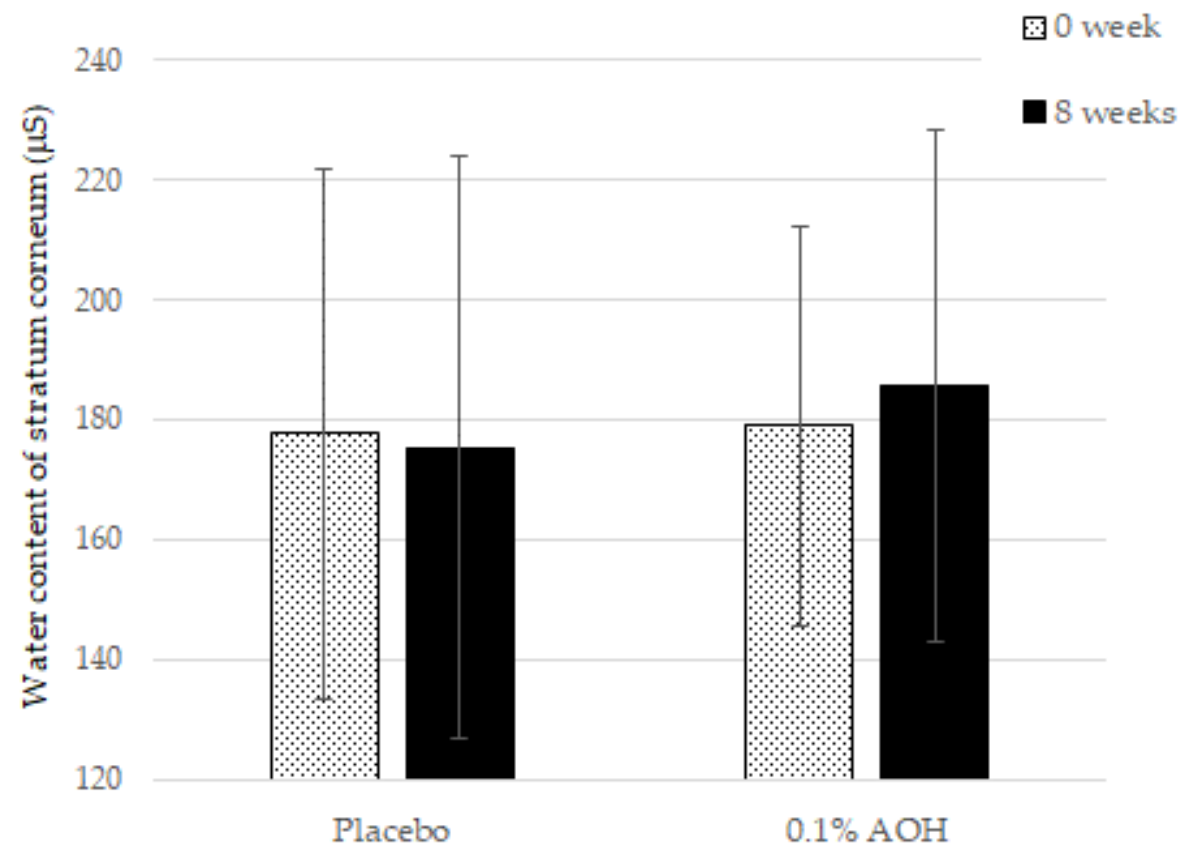

Figure 2. Water content of stratum corneum at the beginning of the study and after eight weeks.

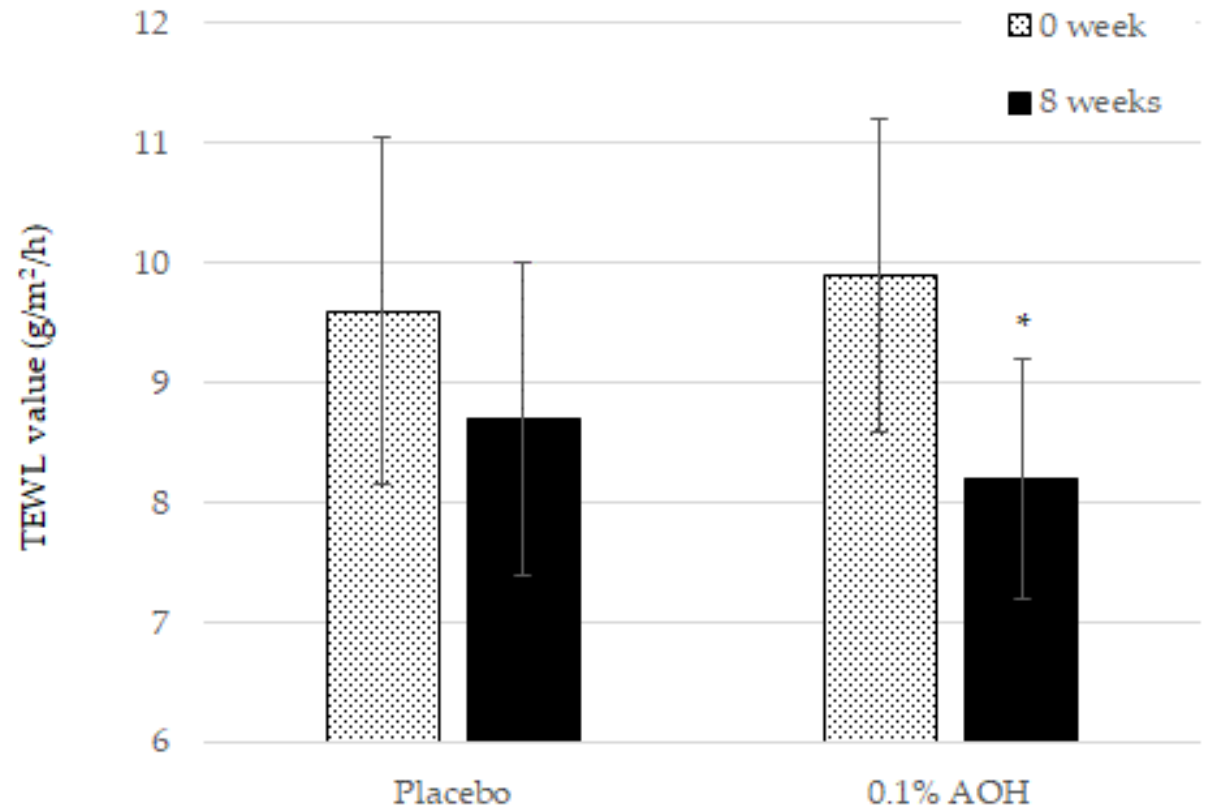

Figure 3. Trans-epidermal water loss (TEWL) value at the beginning of the study and after 8 weeks; ${ }^{*} p<0.05$ vs. 0 weeks.

\section{Discussion}

This study is the first report to show that $\mathrm{AOH}$ has the effect of decreasing TEWL. In a previous study, DNA microarray results showed that $\mathrm{AOH}$ increased the expression levels of genes involved in skin barrier functions such as intercellular adhesion, stratum corneum exfoliation, and differentiation induction in a concentration-dependent manner [15]. In particular, the expression levels of KRT1 and KRT10, which are differentiation markers of 
stratum corneum, were statistically significantly increased at $30 \mu \mathrm{g} / \mathrm{mL}$ of $\mathrm{AOH}$ or higher, suggesting that $\mathrm{AOH}$ may contribute to the promotion of stratum corneum differentiation. The expression level of HAS3, a type of hyaluronic acid synthase, also increased in a concentration-dependent manner with the addition of $\mathrm{AOH}$, suggesting its moisturizing effect. Thus, $\mathrm{AOH}$ might play a role in improving or enhancing the barrier function of the skin. The decrease in TEWL after the application of $0.1 \% \mathrm{AOH}$ lotion was thought to be due to the improvement or enhancement of skin barrier function by $\mathrm{AOH}$. The results of this clinical study were considered as evidence to support the DNA microarray data.

The skin protects the body from physical damage, toxic substances, and pathogen invasion. It also plays an important role in regulating the body's homeostasis by minimizing TEWL through the stratum corneum. In other words, the human skin, especially the stratum corneum, functions as a barrier between the internal and external environments. A decrease in barrier function due to skin aging is believed to be caused by a decrease in filaggrin, a natural moisturizing factor synthesized by keratinocytes, due to the decrease in the differentiation function of keratinocytes [17]. Therefore, regulating the barrier function of the stratum corneum is extremely important for protecting the body. Based on the results of clinical trials and DNA microarrays, $\mathrm{AOH}$ may be a promising cosmetic ingredient for maintaining homeostasis of the skin barrier function. However, the mechanism by which $\mathrm{AOH}$ increases the expression levels of barrier function-related gene groups remains to be elucidated. In the future, we need to clarify the mechanism by which $\mathrm{AOH}$ acts on those genes.

\section{Conclusions}

In the present study, a clinical trial was conducted to verify the effect of $\mathrm{AOH}$ on the skin barrier function in human skin. The results revealed that the stratum corneum water content increased and TEWL decreased significantly after eight weeks of $\mathrm{AOH}$ application, demonstrating that $\mathrm{AOH}$ affects the skin barrier function and can be used as a cosmetic agent.

Author Contributions: Conceptualization, H.A. and R.I.; methodology, H.A.; investigation, H.A. and M.I.; resources, H.A. and H.K.; data curation, H.A., M.I. and R.I.; writing-original draft preparation, H.A.; writing-review and editing, M.I., R.I. and H.K.; visualization, H.A.; supervision, H.K.; project administration, H.A.; funding acquisition, H.K. All authors have read and agreed to the published version of the manuscript.

Funding: This study was funded by Vitamin C60 BioResearch Corporation (Tokyo, Japan). This work was partially supported by a Grant-in-Aid for Scientific Research on Innovative Areas ("Frontier Research on Chemical Communications"; JP17H06402) from MEXT and a Grant-in-Aid for Specially Promoted Research "Science of Fairy Chemicals and Their Application Development" (JP20H05620) from JSPS.

Institutional Review Board Statement: The study was conducted according to the guidelines of the Declaration of Helsinki and approved by the Institutional Ethics Committee of Nikoderm Research Inc. (Approval Number 16000097; date of approval: 10 January 2020).

Informed Consent Statement: Informed consent was obtained from all subjects involved in the study.

Data Availability Statement: The data presented in this paper are available from the corresponding author upon reasonable request.

Acknowledgments: We thank Yoshida and Hayashi of Nikoderm Research Inc. (Osaka, Japan) for performing the clinical trial.

Conflicts of Interest: This study was funded by Vitamin C60 BioResearch Corporation. Hisae Aoshima, Masayuki Ito, and Rinta Ibuki are employees of Vitamin C60 BioResearch Corporation. 


\section{References}

1. Ramsbottom, J. Rate of growth of fungus rings. Nature 1926, 117, 158-159. [CrossRef]

2. Smith, J.D. Fungi and turf diseases. J. Sports Turf. Res. Inst. 1957, 10, 324-352.

3. Shantz, H.L.; Piemeisel, R.L. Fungus fairy rings in Eastern Colorado and their effect on vegetation. J. Agric. Res. 1917, 11, 191-245.

4. Choi, J.-H.; Fushimi, K.; Abe, N.; Tanaka, H.; Maeda, S.; Morita, A.; Hara, M.; Motohashi, R.; Matsunaga, J.; Eguchi, Y.; et al. Disclosure of the "fairy" of fairy-ring-forming fungus Lepista sordida. Chembiochem 2010, 11, 1373-1377. [CrossRef] [PubMed]

5. Choi, J.-H.; Abe, N.; Tanaka, H.; Fushimi, K.; Nishina, Y.; Morita, A.; Kiriiwa, Y.; Motohashi, R.; Hashizume, D.; Koshino, H.; et al. Plant-growth regulator, Imidazole-4-Carboxamide, produced by the fairy ring forming fungus Lepista sordida. J. Agric. Food Chem. 2010, 58, 9956-9959. [CrossRef] [PubMed]

6. Choi, J.-H.; Ohnishi, T.; Yamakawa, Y.; Takeda, S.; Sekiguchi, S.; Maruyama, W.; Yamashita, K.; Suzuki, T.; Morita, A.; Ikka, T.; et al. The source of "fairy rings": 2-Azahypoxanthine and its metabolite found in a novel purine metabolic pathway in plants. Angew. Chem. Int. Ed. 2014, 53, 1552-1555. [CrossRef] [PubMed]

7. Mitchinson, A. Fairy chemicals. Nature 2014, 505, 298. [CrossRef]

8. Asai, T.; Choi, J.-H.; Ikka, T.; Fushimi, K.; Abe, N.; Tanaka, H.; Yamakawa, Y.; Kobori, H.; Kiriiwa, Y.; Motohashi, R.; et al. Effect of 2-Azahypoxanthine (AHX) produced by the fairy-ring-forming fungus on the growth and the grain yield of rice. Jpn. Agric. Res. Q. JARQ 2015, 49, 45-49. [CrossRef]

9. Tobina, H.; Choi, J.-H.; Asai, T.; Kiriiwa, Y.; Asakawa, T.; Kan, T.; Morita, A.; Kawagishi, H. 2-Azahypoxanthine and imidazole-4carboxamide produced by the fairy-ring-forming fungus increase wheat yield. Field Crop. Res. 2014, 162, 6-11. [CrossRef]

10. Kawagishi, H. Fairy chemicals-A candidate for a new family of plant hormones and possibility of practical use in agriculture. Biosci. Biotechnol. Biochem. 2018, 82, 752-758. [CrossRef] [PubMed]

11. Kawagishi, H. Are fairy chemicals a new family of plant hormones? Proc. Jpn. Acad. Ser. B 2019, 95, 29-38. [CrossRef] [PubMed]

12. Baran, R.; Maibach, H.I. Textbook of Cosmetic Dermatology, 5th ed.; CRC Press: Boca Raton, FL, USA, 2017 ; pp. 113-116.

13. Aoshima, H.; Hyodo, S.; Ibuki, R.; Wu, J.; Choi, J.-H.; Kawagishi, H. Safety evaluation of 2-aza-8-oxohypoxanthine based on in vitro and human patch tests. Fundam. Toxicol. Sci. 2020, 7, 207-214. [CrossRef]

14. Aoshima, H.; Matsumoto, T.; Ibuki, R.; Kawagishi, H. Safety evaluation of 2-aza-8-oxohypoxanthine by in vitro skin sensitization and human tests. Fundum. Toxicol. Sci. 2021, submitted.

15. Aoshima, H.; Ito, M.; Ibuki, R.; Kawagishi, H. The potential of 2-aza-8-Oxohypoxanthine as a cosmetic ingredient. Cosmetics 2021, 8, 60. [CrossRef]

16. Choi, J.-H.; Kikuchi, A.; Pumkaeo, P.; Hirai, H.; Tokuyama, S.; Kawagishi, H. Bioconversion of AHX to AOH by resting cells of Burkholderia contaminans CH-1. Biosci. Biotechnol. Biochem. 2016, 80, 2045-2050. [CrossRef] [PubMed]

17. Contet-Audonneau, J.L.; Jeanmaire, C.; Pauly, G. A histological study of human wrinkle structures: Comparison between sun-exposed areas of the face, with or without wrinkles, and sun-protected areas. Br. J. Dermatol. 1999, 140, 1038-1047. [CrossRef] [PubMed] 